الزيارات الميدانية التبادلية ودورها فى نشر المستحدثات الزراعية بمنطقى وادى النقرة ووادى الصعايدة بمحافظة أسوان

\author{
د. محمد عبد العليم على على الرميلى

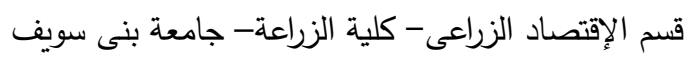 \\ الملخص العربى
}

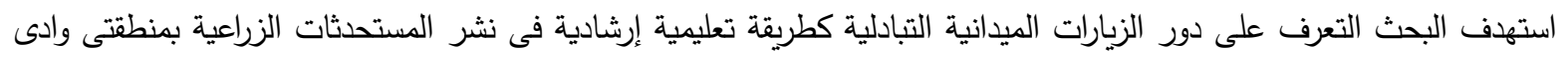

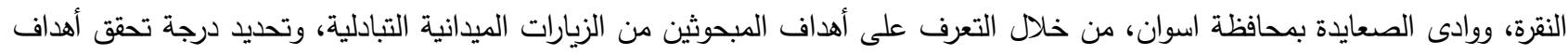
المبحوثين من الزيارات، ومعرفة أوجه استفادة المبحوثين من تعرضهم للزيارات بمنطقة مشروع غرب النوبارية، ومعرفة امكانية تتفيذ المبحوثين للمستحدثات التى تعرضوا لها فى الزيارات الميدانية مستقبلاً. أجرى البحث على شاملة قدرها ه ب مبحوثاً من أعضاء الجمعيات التعاونية التسويقية الزراعية لإنتاج وتسويق الحاصلات الزية الزراعية

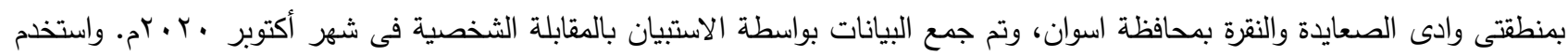

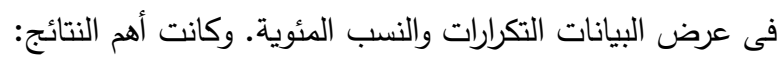
تعدد وتتوع أوجه الاستفادة من الزيارة الميدانية التبادلية لدى المبحوثين من اكتساب معارف ومهارات ولثات جديدة، وتحقيق مكاسب اجتماعية.

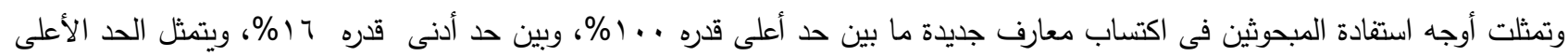

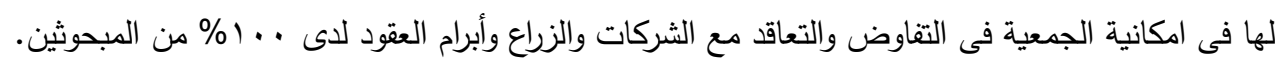

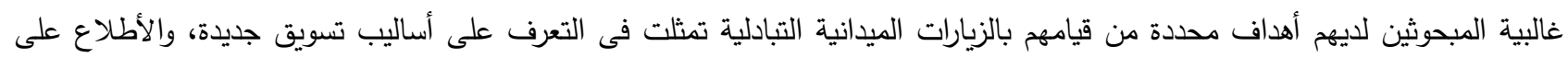

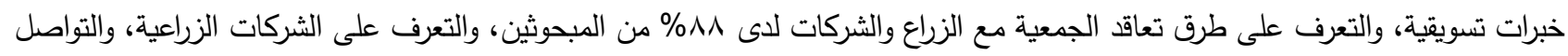

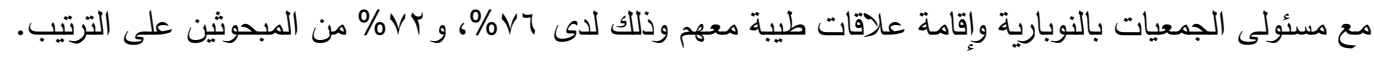

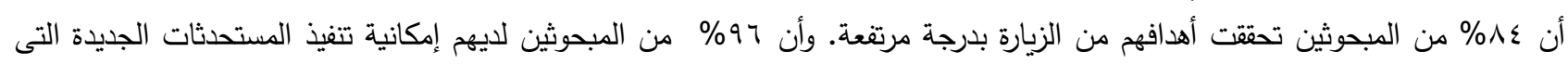
تعرضوا لها فى الزيارة فى المستقبل، وأن جو\% من المبحوثين يرون أن مستوى تتظيم الزيارات بين مرتفع وتوسط. الكلمات الدالة: الزيارات الميدانية/ التبادلية- الطرق الإرشادية- يوم الحقل- الرحلات الإرشادية.

ويصنف الإرشاد الزراعى بأنه عملية تقديم المعلومات والتكنولوجيا إلى الزراع ليمكنهم من تحسين انتاجيتهم ودخلهم وشئون معيشتهم، ومساعدتهم على تبنى تقنيات جديدة، وعلى تحسين أساليب التسويق، وتحسين المهارات الإدارية من خلال استخدام مجموعة متتوعة من مناهج الإرشاد الزراعى لتعزيز تعليم وتدريب مستهدفيه إعتماداً على أساليب الزراعة الحديثة. ولكى يحقق الإرشاد الزراعى أهدافه فأنه يستخدم طرقاً إرشادية عديدة ومتتوعة لحمل رسائله الإرشادية التي يرغب فى نقلها إلى جمهور مستهدفيه، ويتوقف نجاح الإرشاد الزراعى فى تحقيق أهدافه على مدى حدوث الاستجابة المرجوة لاي مستقبلي الرسائل الإرشادية. وعليه فلابد من توفر الشخص الذى سيقوم بالعمل الإرشادى ذو القدرات الاتصالية وذو

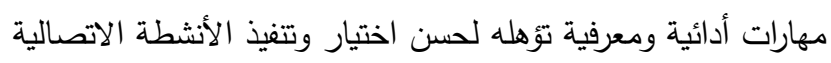

\section{ا ـ المقدمة ومشكلة البحث}

تعتمد الزراعة فى الوقت الحاضر على التكنولوجيا الحديثة وتطبيقاتها المختلفة لفهم المتغيرات العديدة المرتبطة بالعمليات الزراعية والتغلب عليها من خلال الاستفادة من التقنيات الرقمية فى إدارة المزارع بأسلوب يزيد من كفاءة وانتاجية المزرعة بدون زيادة لمواردها المستخدمة.

فقد مرت الزراعة من مرحلة استئناس الزراع للنباتات البرية والحيوانات إلى مرحلة استخدام الآلة الحديثة فى عمليات إعداد

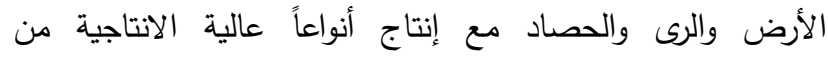
المحاصيل الحقلية، مروراً بالفترة الحالية التى تدعم أساليب الرى الحديث مع تطوير المستحدثات الزراعية التى تؤدى إلى مضاعفة الانتاج مع تقليل الفقد والهدر فى المحاصيل المنزرعة بشكل عام. 


\section{Scientific Journal of Agricultural Sciences 2 (2): 279-290, 2020}

Field Schools، وقوافل التعلم Learning caravans، وأحياناً

تستخدم هذه المصطلحات بالتبادل.

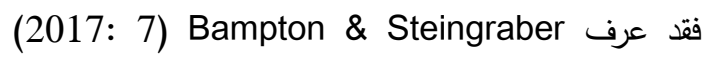
الزيارة الميدانية Site Visits بأنها الأنشطة التي يكتسب من خلالها

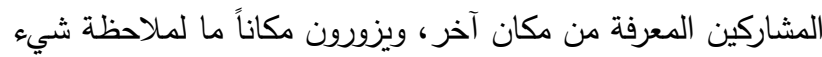
محدد والتفاعل مع الأشخاص الذين هم على دراية به. وتتفذ الزيارة الميدانية لأهداف التعلم دائماً.

ويشير هذا التعريف بشكل عام إلى جميع النماذج المختلفة

للزيارات الميدانية مثل الرحلات، والزيارات الحقلية، والزيارات التبادلية، ومؤتمر، وقافلة تعليمية. ويؤكد أيضاً على أن الأهم من الزئرات الترات



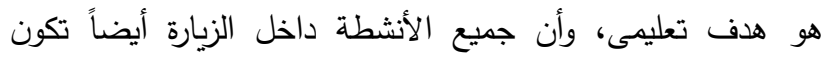

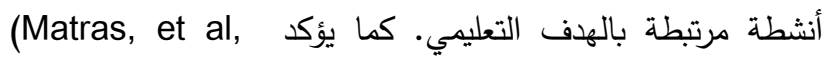
2013:2) أن الزيارات التبادلية تسمى أيضاً بالرحلات الدراسية ،"Exchange visits, which are also called study tours" وهى تهذف إلى تحسين معرفة وممارسات الزوار ومنظماتهم، ودمج الخبرة المكتسبة من الزيارة في حياتهم اليومية. وتعرف الزيارات التبادلية Exchange visits على أنه النهائه تتظيم اجتماع بين مجموعة من الزوار من جهة تتكون من أربعة إلى

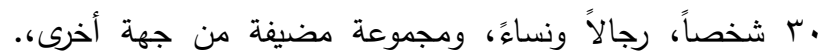

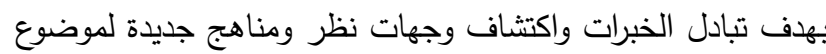
محدد. ويختلف الموقع الجغرافي لهذه الزيارات حسب توقعات

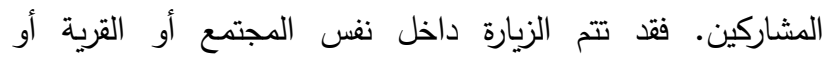
المحافظة، أو بين مجتمعات أو قرى أو محافظات أو دول مختلفة.

(Matras, et al, 2013:2)

يوجد العديد من الدوافع لتنظيم وتتفيذ الزيارات الميدانية

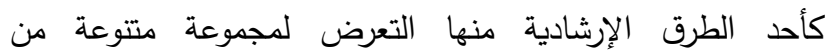
الممارسات والتقنيات الجديدة التى لم تكن موجودة من قبل لإظهار نتائج ملموسة وعملية، ولتطوير المهارات الفنية والتدريب على مهارة

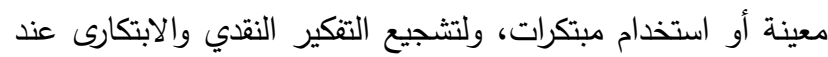

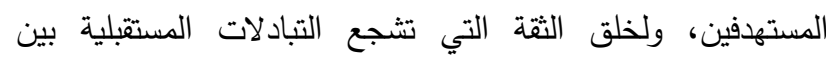
المستهدفين، وربط المجموعات وانشاء شبكات للمشاركة المستمرة أو

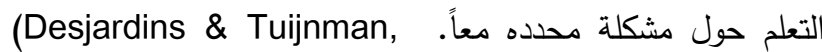
2005: 359) ويؤكد البنك الدولى (World Bank, 2015) على أن تبادل المعرفة الناتج من تبادل الزيارات يينى القدرة والثقة والقناعة لاى الأفراد والجماعات للعمل. وذلك لعده أسباب محتملة أهمها القيام بأنشطة تبادل المعرفة خلال الزيارات الميدانية وهى ربط مستهدفى
بكفاءة وفاعلية. واختيار الطريقة التي تتاسب مختلف المواقف التعليمية عند تخطيط البرامج التعليمية الإرشادية، وأن يكون لها تأثير مباشر على العملية التعليمة الإرشادية كما وكيفاً. يبين Neil \& Putso الإرشادية فاعلية فى العمل الإرشادى الزراعى هى الجولات الميدانية/

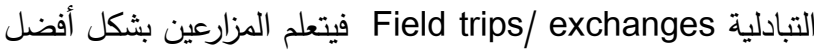
عن عن طريق أقرانهم ممن طبقوا الأفكار المستحدثة. وأكد Neil

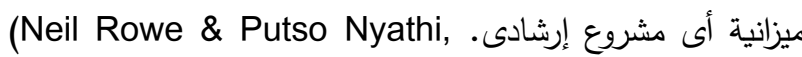
2017: 5-7)

وأشار Heiniger وآخرون (2002:308) أن أيام الحقل

Field days

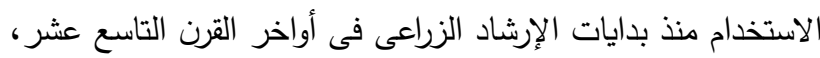
وأصبحت من الطرق الإرشادية الرئيسية الدستخدمة فى إدخال

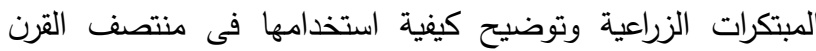
العشرين. إلا أنه مع التقدم فى خدمات الاتصالات، وارتفاع تكلفة

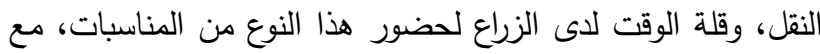

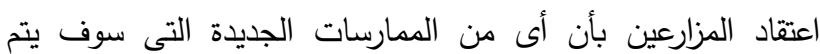
نشرها حالياً أو مستقبلاً لا تختلف كثيراً بل تشبه فى استخدامها للممارسات السابقة والمستخدمة بالفعل في مزارعهم الحديثة. تسبب فى انخفاض استخدام أيام الحقل والرحلات كطريقة إرشادية تعليمية.

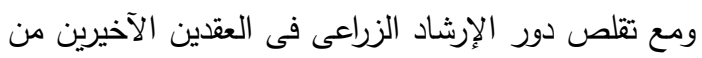

القرن العشرين فى القيام بالأنشطة الإرشادية الزراعية نتيجه لتقلص

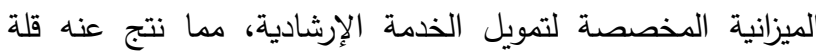

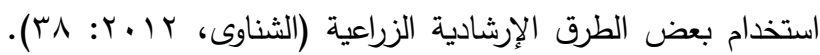

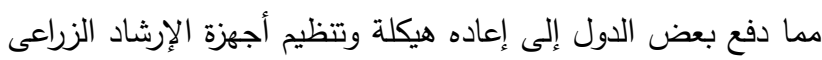

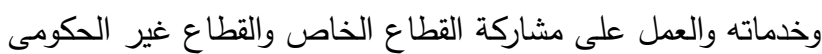
والمنظمات التتموية المحلية والدولية فى تقديم الخدمات الإرشادية.

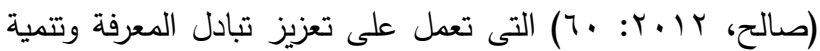

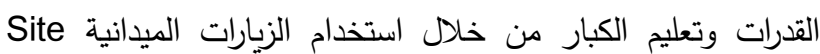
Visits

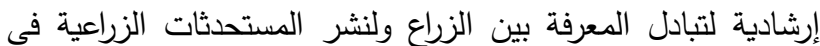
مجتمعاتهم فى جميع أنشطتها الإرشادية.

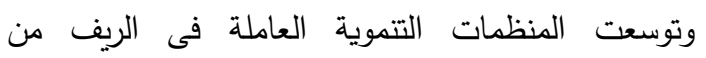
Site Visits استخدام نماذج متعددة ومختلفة للزيارات الميدانية ونوعت من استخدام مصطلاحاتها مثل الرحلات Tours، وتبادل Farmer Exchange visits الزيارات والمدارس الحقلية للمزارعين 
ومع ذلك، فإن الزيارات الميدانية قد ينتابها بعض العيوب منها إرهاق السفر، وركوب وسائل مواصلات مملة، وسرعة أنجاز

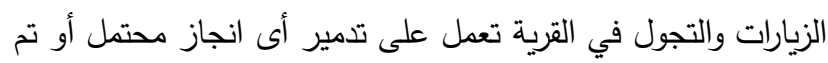
القيام به. وقد يكون المضيفون أو الزوار غير مستعدين أو غير تأولير قادرين على التواصل مع بعضهم البعض. وأن يعتقد المشاركون بأن

الزيارات التبادلية ما هى إلا عطله وتتزه وترفيه. (Bruns, B, (12002: 12) والأعداد لأماكن الأقامة وأماكن الزيارات وتجهيزات القاعات، وأماكن الأكل والضيافة قد تزعج المشاركين والقائمين بالزيارة، وتستنفد الصبر

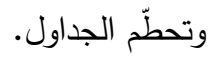

يوجد فى دول العالم النامية العديد من المنظمات المحلية التتموية التي تساعد العائلات فى المجتمعات الريفية الفقيرة. إلا أن تلك المنظمات تفقد التنسيق فيما بينها، ونتيجة لذلك لا يتم دائماً نقل الدروس المستفادة في إحدى المنظمات إلى المجموعات الأخرى. ولتقوية المنظمات المحلية العاملة فى الريف هي مساعدتهم على التعلم من بعضهم البعض، وأفضل طريقة للتعلم من منظمات المجتمع المحلي أو المنظمات غير الحكومية الأخرى هي زيارتها ورؤية ما تفعله أمامها. (Lentfer, j, 2011) ومن منطلق تعددية الخدمة الإششادية قامت الدولة المصرية ممثلة فى وزارة الزراعة واستصلاح الأراضى بتوقيع اتفاقية

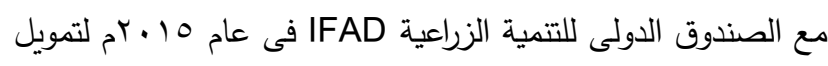
مشروع الاستثمارات الزراعية المستدامة SAIL وذللك على غرار

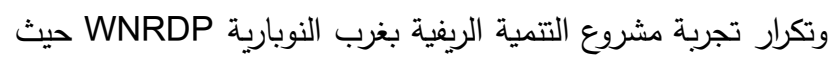

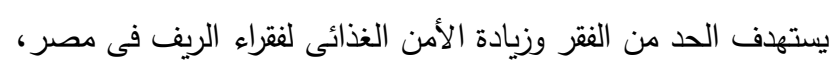
والعمل على أن يصبح صغار الزراع قادرين على مواجهة الفقر من خلال زيادة دخلهم وتحسين ارباحهم وتتوع سبل معيشتهم. وأيضاً تحسين الاوضاع الاجتماعية والاقتصادية للفئات المستهدفة بمناطق عمل المشروع. ومن المناطق المستهدفة منطقة وادى النقرة ووادى الادي الصعايدة بمحافظة أسوان، وقد قام المشروع من خلال المكون

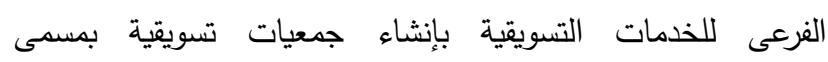
الجمعيات التعاونية الزراعية لإنتاج وتسويق الحاصلات الزراعية بمنطقى النقرة ووادى الصعايدة، بهدف دعم التعاونيات الزراعية

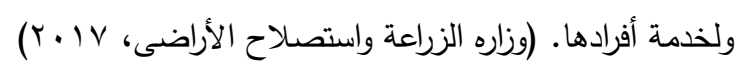

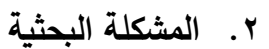

نتيجة لما تشهده الزراعة من تقدم تقنى عالى المستوى فى المى الآونة الأخيرة من إدراج تقنيات حديثة وأنتشارها فى الأنظمة المزرعيه مثل أنظمة (DGPS)، ونظم المعلومات الجغرافية (GIS)، وأنظمة التوجيه الالكترونية، والممارسات الزراعية المستحدثة القائمة على هذه
الزيارات بالمعلومات والفرص الجديدة عبر البلدان والمناطق التى يتم زيارتها، وتحفيز التفكير الابتكاري وإيجاد حلول تتموية أفضل، وإلهام التعاون بين الأفراد أو المؤسسات أو البلدان أو المناطق، والإسراع في اتخاذ القرار والإصلاح. كما تقدم الزيارات التبادلية مجموعة من المزايا، تتجاوز مجرد الحصول على المعلومات. فهى تشكل العلاقات وتخلق تفاهماً مشتركاً بين المشاركين نتيجة لمتعة وصعوبات التجربة المشتركة، وتكون صداقات للتواصل في المستقبل، والتعلم بعمق، وتبادل الأفكار، وتقييم أهمية الأساليب الجديدة المستخدمة للمسافرين والمضيفين. وتمتاز أيضاً بأن المعلومات تأتى بطريقة مباشرة في

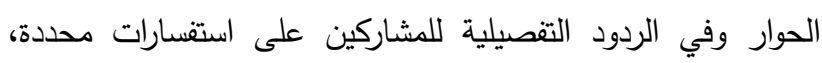
وأنها تخلق الإلهام لمواصلة العمل وإطلاق مبادرات جديدة نتيجة التعرف على أناس حقيقيين، وفهم مشاكلهم وإنجازاتهم. Bruns, B, 2002: 1-12)

ويؤكد البنك الدولى (World Bank, 2015) على أن الزيارات الميدانية/ التبادلية يمكن أن تكون أداة مفيدة، وفعالة عندما يتم التحضير لها بدقة وبشكل صحيح لتجنب إضاعة وقت الزوار والمضيفين. فالمزارعون يحبون زيارة المزارع في مناطق أخرى لمعرفة كيف يعملون، وماذا يزرعون وأنواع المشاكل التي يواجهها المزارعون فى بلادهم. وعادة ما تكون التقسيرات أكثر فاعلية عندما يتم عرضها من قبل المزارعين الذين يقومون باستخدم تلك الممارسات التي تتم دراستها.

فالتسيق الجيد للزيارات التبادلية يتيح مجالاً كبيراً للمزارعين لتتمية قدراتهم، وتعطى فرصة للتعلم على عدة مستويات وفقاً لمراحل التبنى (سلم التبنى). من إعلام المزارع بالممارسة

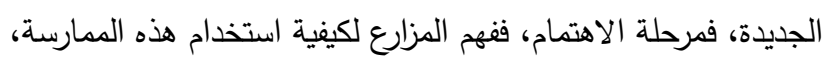

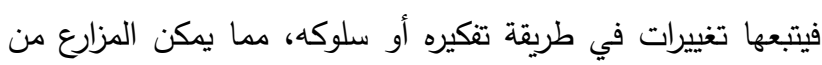
ترجمة الفكرة إلى عمل، فيؤدي إلى التبني وفقاً للظروف المحلية. ،(Matras, et al, 2013:2) وقد بين (Maddy, B. et al, 2015) أن التخطيط المبكر أهم عنصر فى خطوات تتغيذ رحلة ميدانية ناجحة. وتحديد هدف واضح ومتفق عليه من جميع أصحاب المصلحة. وأن يكون هدف كل زيارة داخل الرحلات أو الزيارات الميدانية متوافق مع هع الهدف الرئيسى للزيارة. مع تضمين هدف تعليمي لكل زيارة من الزيارات الميدانية ويعلن بها جميع الأطراف المعنية بالهدف منها والنتيجة المرجوة، مع توضيح ما هي المفاهيم التي يجب على لئ المشاركين فهمها أو القيام بها أو تطبيقها. 


\section{Scientific Journal of Agricultural Sciences 2 (2): 279-290, 2020}

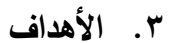

وإتساقاً مع مقدمة البحث ومشكلته أمكن صياغة الأهداف

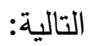

•التعرف على أهداف المبحوثين من الزيارة لمنطقة مشروع غرب

$$
\text { النوبارية. }
$$

تحديد درجة تحقق هدف المبحوثين من الزيارة لمنطقة مشروع

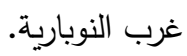

التعرف على مصادر معرفة المبحوثين بالمستحدثات الزراعية

$$
\text { الجديدة بمنطقة مشروع غرب النوبارية. }
$$

التعرف على أوجه استفادة المبحوثين نتيجة تعرضهم للزيارات

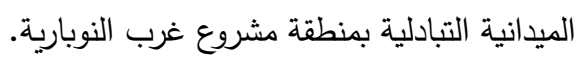

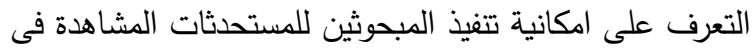

$$
\text { الزيارات الميدانية التبادلية مستقبلاً. }
$$

• التعرف على أراء المبحوثين فى تنظيم الزيارة الميدانية التبادلية

$$
\text { ـ. ل التعريفات مشروع غرب الإجرائية النوبارية. }
$$

الزيارات الميدانية التبادلية exchange site visits: هو تنظيم الاجرئه لقاء بين مجموعتين من خلال قيام مجموعة الزوار بزيارة لمجموعة لزيارة مضيفة والتى لها اهتمامات متشابهة بينهم فى مجال عملهم، للقيام بأنشطة مشتركة تبادلية بهدف التعرف على الستحدثات وتبادل وأكتساب الخبرات وذللك فى مواقع عملهم.

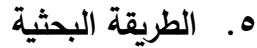

تم إجراء هذا البحث بمنطقى وادى النقرة، ووادى الصعايدة

بمركزى نصر النوبة، وأدفو بمحافظة أسوان، وتمثلت شاملة البحث فى جميع الزراع الششاركين فى الزيارات الميدانية التبادلية إلى منطقة

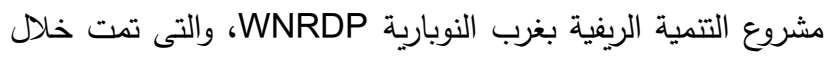

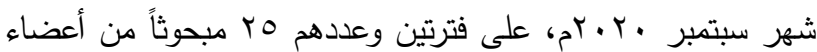

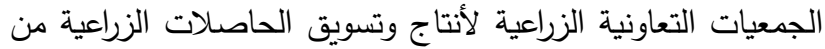

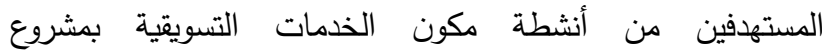
الاستثمارات الزراعية المستدامة وسبل المعيشة SAIL. حيث شملت الزيارة الأولى عدد ץ/ عضواً من منطقة وادى الصعايدة خلال الفتره

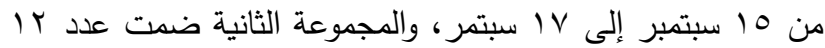
من منطقة وادى النقرة خلال الفترة من rاسبتمبر إلى گr سبتمبر $\cdot r_{T} \cdot r \cdot$

جمعت البيانات بالمقابلة الثخصية من المبحوثين بواسطة

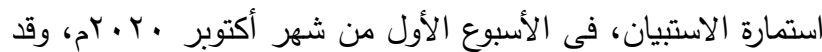

التتنيات الجديدة، التى لم يوجد لها مثيل من قبل لاى الزراع، والتى غيرت من أنظمة إدارة وتشغيل المزرعة والتى تتطلب نوعية من

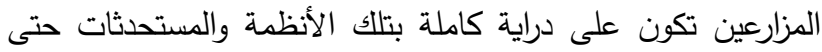

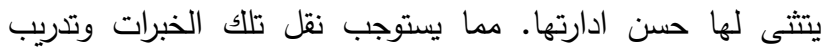

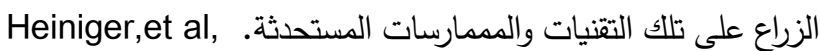

(2002: 309)

ولكى نزيد من سرعه تبني عناصر تلك التقنيات الزراعية

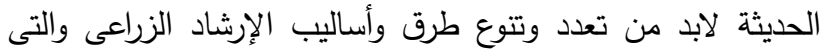
تؤدى بدورها إلى زيادة فاعلية التعليم والتعلم، وتعد الزيارات الميدانية بصورها المختلفة من الطرق الإششادية التى تزيد من فاعلية عملية

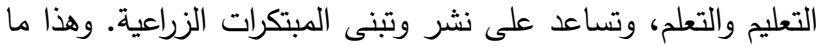
يؤكده Maddy وآخرون(2015) بأن الزيارات والرحلات الميدانية وورش العمل لا تزال طرق مفيدة وذات أهمية في التعليم الإرشادي.

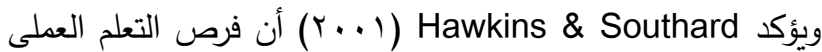
فى الزيارات الميدانية الحقلية لا يمكن تكرارها بنفس الدقة والأسلوب

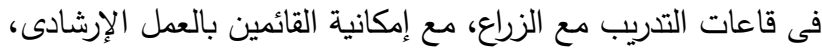
وعلماء الزراعة الاستفادة من الزيارات الميدانية لخلق بيئة من التعلم التجريبي، وزيادة الاحتفاظ بالتعلم إلى أقصى حد ممكن. وهذا ما إستهدفه مشروع SAIL من خلال الدكون الفرعى للخدمات التسويقية، للقيام بإنشاء جمعيات تسويقية بمسمى الجمعيات التعاونية الزراعية لإنتاج وتسويق الحاصلات الزراعية بمنطقتى النقرة ووادى الصعايدة، بهدف دعم التعاونيات الزراعية ولخدمة أفرادها ونشر الأفكار والمستحدثات الزراعية وبخاصة فى مجال التسويق الزراعى. وقد قام المشروع فى الأونة الأخيرة بإشراك أعضاء الجمعيات التعاونية التسويقية بمنطقتى النقرة والصعايدة بمحافظة أسوان بزيارة تبادلية إلى منطقة مشروع التتمية الريفية بغرب النوبارية

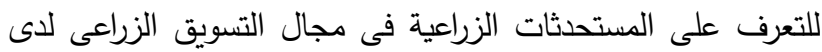

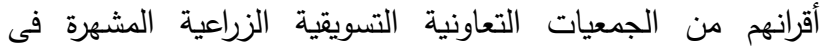
المناطق المختلفة بمنطقة مشروع التنمية الريفية بالنوبارية وذللك لتبادل واكتساب الخبرات فيما بينهم فى المجالات الزراعية المختلفة

كطريقة لنشر المستحدثات والتوصيات الفنية والتسويقية الزراعية. بإستعراض الدراسات السابقة التى تتاولت دور الطرق الإرشادية الزراعية فى نشر التوصيات الفنية الزراعية على مستوى جمهورية مصر العربية، لم يستدل الباحث عن بحوث ودراسات

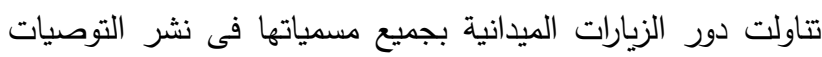
الفنية الزراعية، لذا لزم الأمر إلى إجراء هذا البحث لهعرفة دور

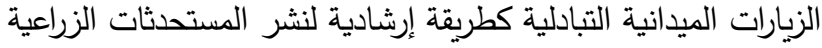
بمنطقتى وادى النقرة، ووادى الصعايدة بمحافظة اسوان. 


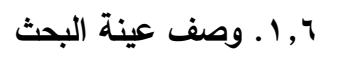

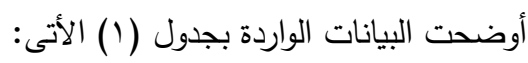
1- السن: أن خمسى المبحوثين •؛ \% يقعون فى الفئة السنية

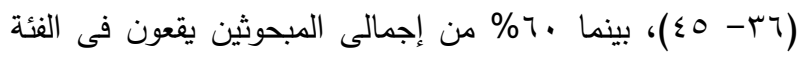

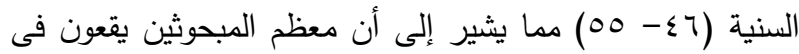
الفئة السنية الكبيرة، وهى فئة من لديهم الخبرات والتى قد يكون لها

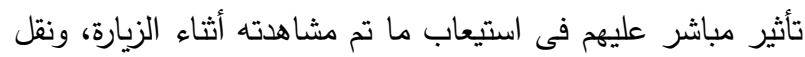

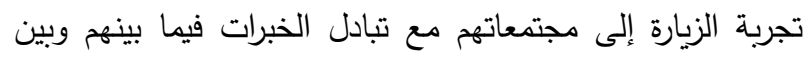
زملائهم من أعضاء الجمعية ممن لم يقوموا بالزيارة.

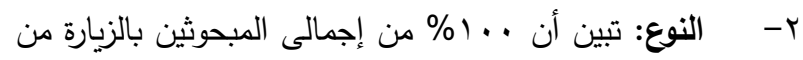

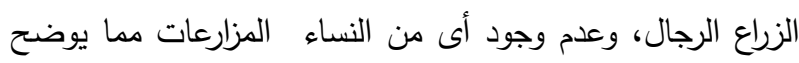

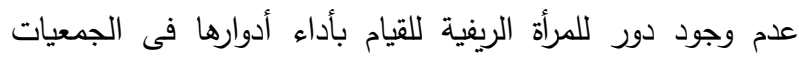

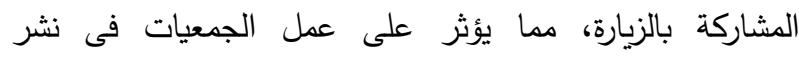
المستحدثات المستهدفة بقرى المبحوثين وتحقيق الأهداف والأنشطة المتعلقة بالمرأة. مما قد يؤثر فى نقل المعارف والمهارات الواجب المبات

استخدامها من قبل المزارعات فى أنشطة الجمعية التسويقية.

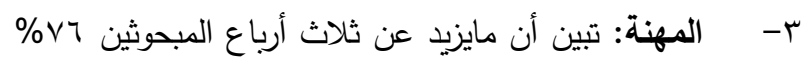
يعملون بمهنة الزراعة فقط، وأصحاب مزارع حيوانية، وداجنة. ويوضح ذلك مدى إعتماد المبحوثين على مهنة الزراعة كمصدر

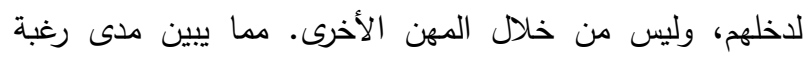

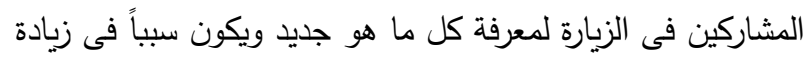

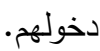

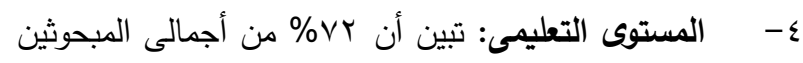

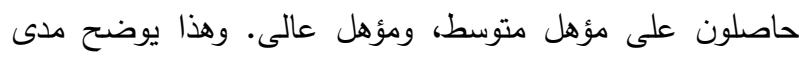

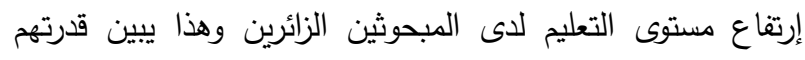
على البحث والاستفسار وتقبل لكل ما هو جديد وقدرتهم على نقله إلى أقرانهم من الزراع بعد عودتهم من الزيارة.

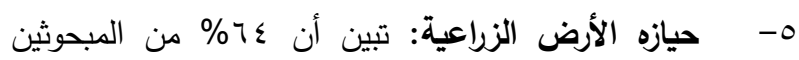

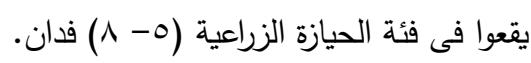

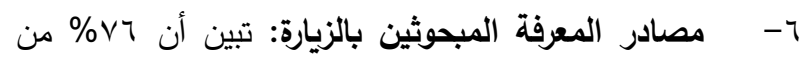

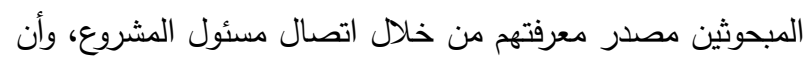

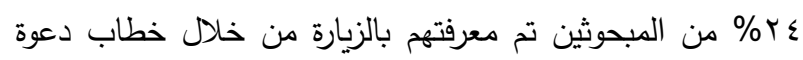

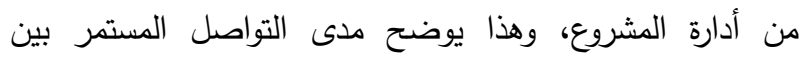
المبحوثين والجهات المسئولة عن تتمية الجمعيات الريفية العاملة

بالمنطقة.

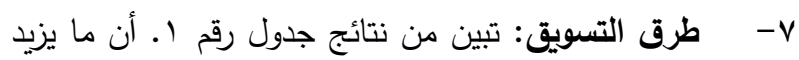

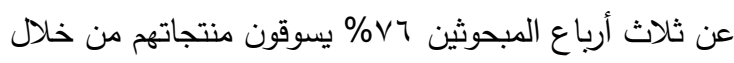

أشتملت إستمارة الإستبيان على مجموعة من الأسئلة التى تحقق الإجابة عليها أهداف البحث. وتم معالجة البيانات المتحصل عليها كمياً على النحو البح التالى: التعرف على أهداف المبحوثين الزائرين من الزيارة الميدانية

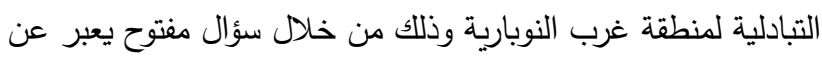
هدف زيارة المبحوث، وجمعت الاستجابات فى عناصر مستقلة.

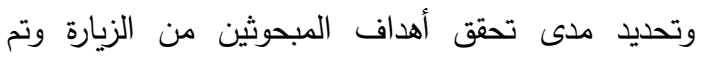
معالجة ذلك من خلال وضع سؤال مفتوح لمعرفة ما تحقق من تلك الك الأهداف، وقد تم تقسيم إستجابات المبحوثين إلى ثلاث فئات دئات وفقاً للدرجة تحقق أهدافهم. وهى مستوى تحقق (منخفض، متوسط، مرتفع). التعرف على مصادر معرفة المبحوثين أثناء الزيارة

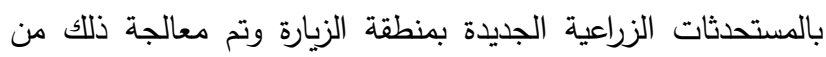
خلال وضع سؤال مفتوح لمعرفة ماهى مصادر معرفة المبحوثين

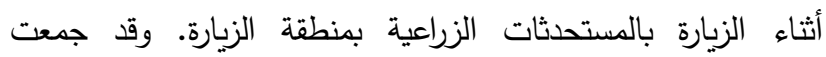
الإستجابات وجمعها فى عناصر مستقلة. وتحديد ما هى أوجه إستفادة المبحوثين من زيارتهم

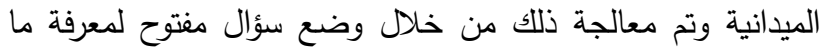
تحقق للمجحوثين من إستفادة لزيارتهم الميدانية. وقد تم جمع الإستجابات وجمعها فى ثلاثة عناصر رئيسية وهى (إكتساب معارف جديدة، وأكتساب مهارات جديدة، وأكتساب مهارات إجتماعية). التعرف على المستحدثات التى سيقوم المبحوثين بتنفيذها

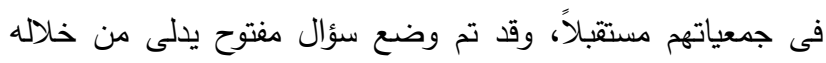
المبحوثين عن المستحدثات التى سيتم تطبيقها فى جميعاتهم نتيجة للزيارة المستهدفة.

التعرف على أراء المبحوثين فى العملية التتظيمية للزيارة الميدانية التبادلية: حيث تم قياسه من خلال سؤال المبحوث عن مكونات التظيم الجيد للزيارة من خلال عبارات تعكس مواصفات

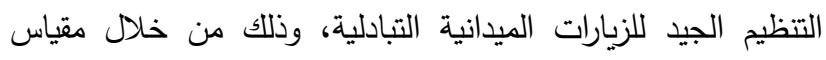
متدرج من ثلاث فئات (مناسبة جداً، مناسبة لحد ما، غير مناسبة)

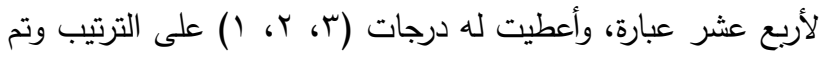

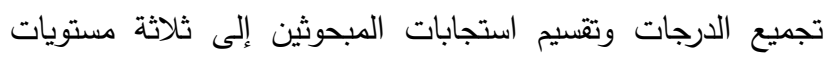

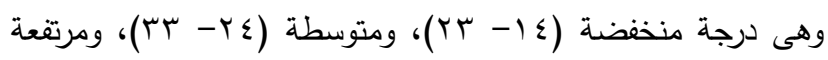

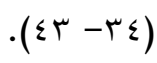
ولتحليل بيانات هذا البحث إحصائياً فقد تم الاستعانة بإحصاءات

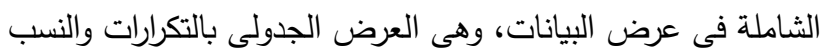
المئوية لكون البحث بحثاً وصفياً.

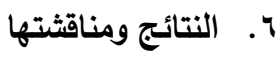


جدول ا ـ توزيع المبحوثين وفقاً لخصائصهم. ن= هب

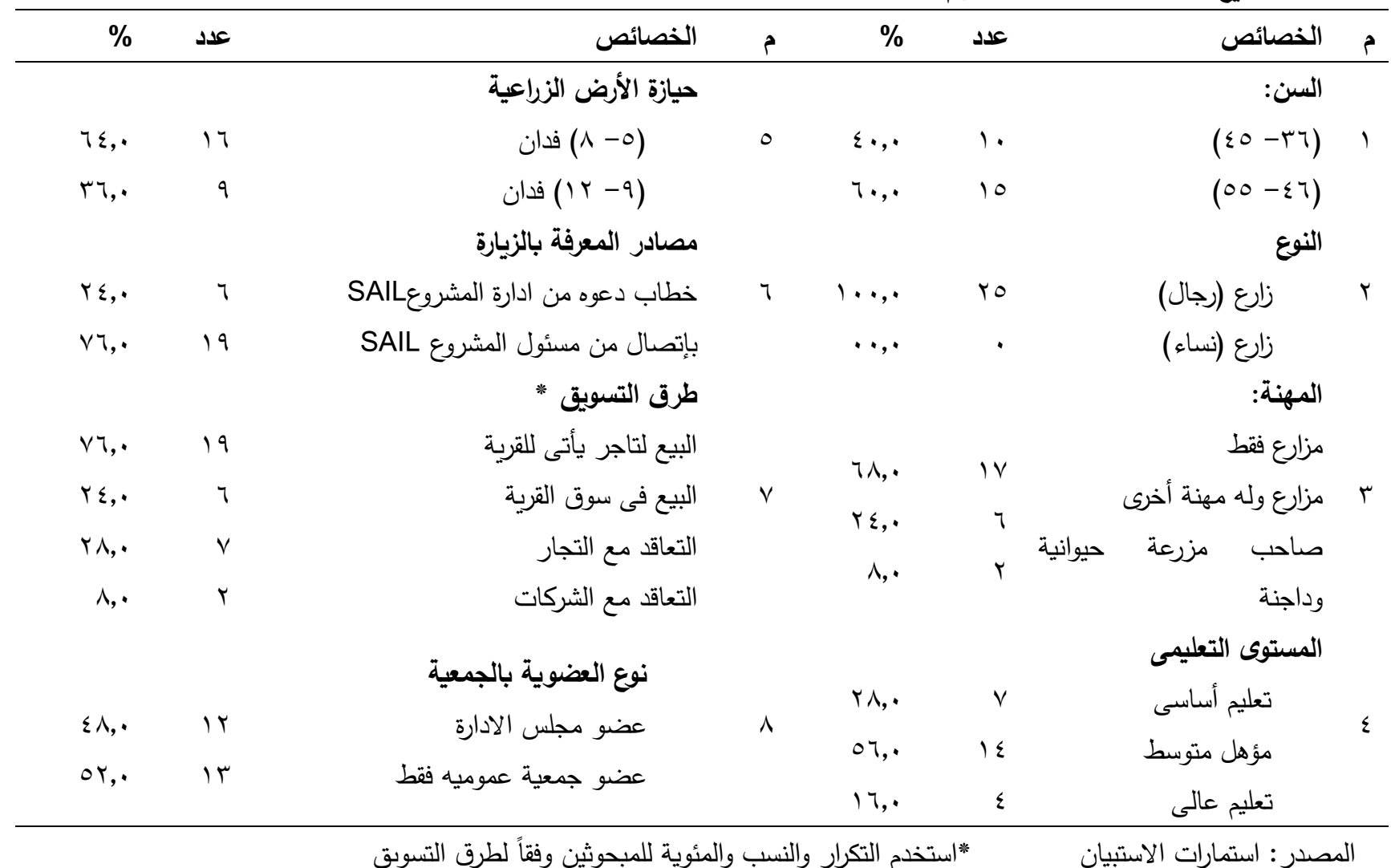

الثركات الزراعية المتعاقدة معها الجمعيات الزراعية التسويقية بالنوبارية.

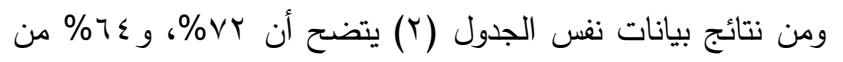

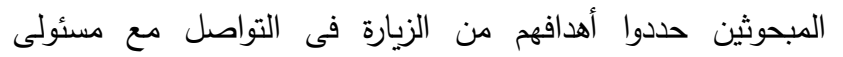

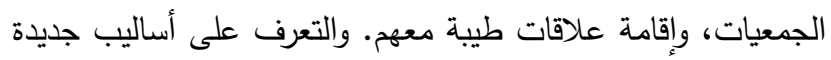

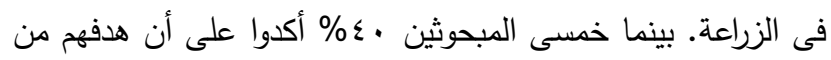
الزيارة يتضمن وقت للترفيه والتنزه.

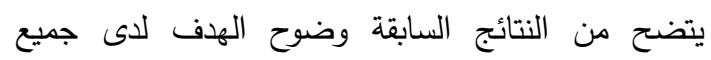
المبحوثين من الزيارة الميدانية والتى تركزت فى أن هدف الدبحوثين

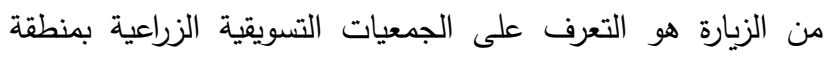

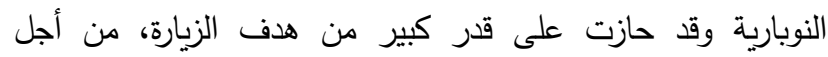
التعرف على كل الأنشطة التى تساعد فى تلى تلمية موارد جمعيات المبحوثين، والتواصل مع مسئولى الجمعيات التسويقية بالنوبارية وأقامة علاقات طيبة معهم، وأيضاً الزيارة من أجل التنزه والترفيه عن بالنيارئ النفس.

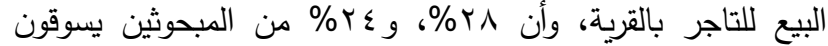
منتجاتهم من خلال التعاقد مع التجار ، والبيع فى سوق التحان القرية. ويبين ذلك أن أساليب التسويق لدى غالبية المبحوثين أساليب تقليدية.

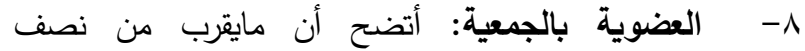

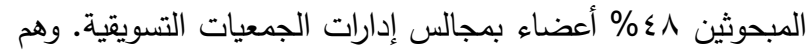
الأعضاء الذين لهم سلطة اتخاذ القرارات بتبنى المستحدثات

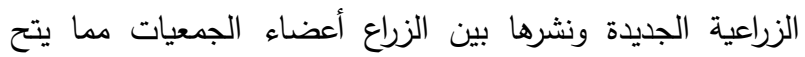
سرعة نشر المستحدثات من خلالهم فى مجتمعاتهم.

Y, Y. التعرف على أهداف المبحوثين من الزيارة الميدانية التبادلية لمنطقة مشروع غرب النوبارية.

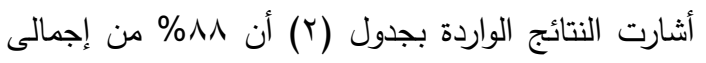

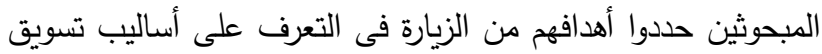

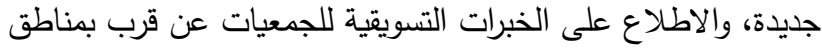
الزيارة، والتعرف على طريقة تعاقد الجمعية مع الزراع ومع الثركات.

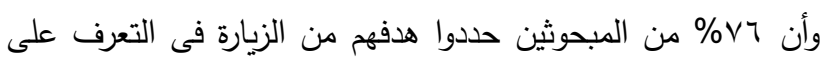


EIramily, M. A. A. A., 2020

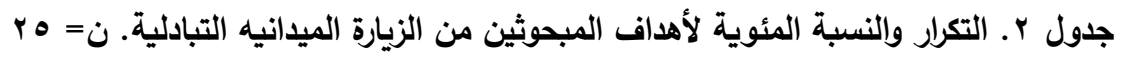

\begin{tabular}{|c|c|c|c|}
\hline$\%$ & 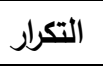 & أهداف الزيارة & 5 \\
\hline$\wedge \wedge$, & rt & التعرف على أساليب تسويق جديدة لدى الجمعيات التسويقية & 1 \\
\hline$\wedge \wedge$, & rr & الاطلاع على خبرات التسويقية للجمعيات عن قرب بمناطق الزيارة & r \\
\hline$\wedge \wedge$, & rr & التعرف على طريقة تعاقد الجمعية مع الزراع ومع الشركات & r \\
\hline$\vee 7, \cdot$ & 19 & التعرف على الشركات الزراعية المتعاقدة معها الجمعيات & $\varepsilon$ \\
\hline$V Y, \cdot$ & 11 & التواصل مع مسئولى الجمعيات وإقامة علاقات طيبة معهم & ○ \\
\hline $7 \varepsilon$, & 17 & التعرف على أساليب جديدة فى الزراعة & 7 \\
\hline$O$, $_{\text {, }}$ & 14 & التعرف على محاصيل للتصدير & v \\
\hline or,. & ir & التعرف على اجابات لأسئلة عن أساليب التسويق المتبعة & $\wedge$ \\
\hline$\varepsilon \wedge$, & ir & التعرف على المحاصيل المزروعة فى المنطقة وبتسوقها الجمعيات & 9 \\
\hline$\varepsilon \varepsilon$, & 11 & التعرف على المشاكل اللى بتواجه الجمعيات فى التسويق & $1 \cdot$ \\
\hline$\varepsilon \wedge$, & ir & التعرف على أماكن جديدة & 11 \\
\hline$\varepsilon \cdot, \cdot$ & $1 \cdot$ & وقت للترفيه والتتزه & ir \\
\hline r.,. & 9 & نشوف جمعيات بتسوق بطريقة مختلفة عن جمعياتنا & ir \\
\hline
\end{tabular}

المصدر : إستمارة الإستبيان

بدرجة مرتفعة، ومتوسطة. بينما نجد أن ع٪ من المبحوثين لم تحقق الزيارة هدفه منها.

ويتضح من العرض السابق أن الزيارة قد حققت أهداف

المبحوثين المنشودة، وهذا يتضمن نجاح الزيارات الميدانية التبادلية

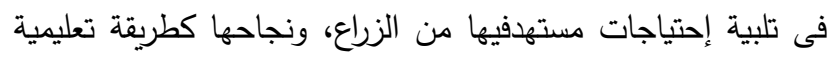
إرشادية من خلال تحقيقها لأهداف الزراع الششاركين فى الزيارة .
ז,بـ. درجة تحقق هاف المبحوثين من الزيارة الميدانية التبادلية لمشروع غرب النوبارية

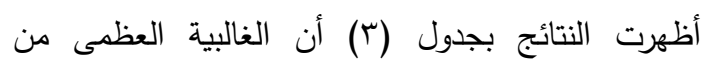

المبحوثين الزائرين لكنطقة النوبارية 97\% قد تحقق هدفهم من الزيارة

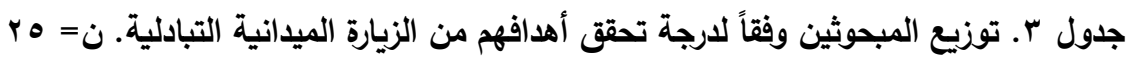

\begin{tabular}{|c|c|c|c|}
\hline$\%$ & عدد & \multicolumn{2}{|c|}{ درجة تحقق الأهداف المنشوده } \\
\hline$\wedge \varepsilon, \cdot$ & Yl & تحقق الهدف بدرجة مرتفعة & - \\
\hline Ir,. & r & تحقق الهذف بدرجة متوسطة & - \\
\hline$\varepsilon$, & 1 & تحقق الهـف بدرجة منخفضة & - \\
\hline $1 \ldots$, & ro & & المجموع \\
\hline
\end{tabular}

المصدر : إستمارة الإستبيان

المبحوثين، وأن أقل المصادر المعرفية لهم أثناء الزيارات هو المشرف عن الزيارة لاى ؟ \% فقط.

وهذه النتائج تدل على أن مصادر المعرفة فى الزيارات

الميدانية التبادلية تتمثل فى المصادر ذات التأثير المباشر ، والمتمثلة فى الثخص المسئول عن تطبيق وتتفيذ ومتابعة المستحدث (رئيس

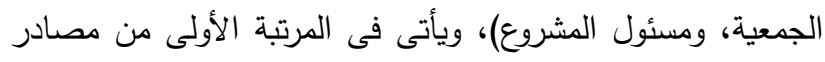

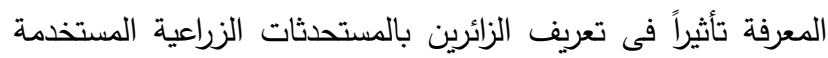
لديه، لذا وجب عند القيام بزيارات ميدانية أخرى تحديد المسئول الأول
\, ؛. مصادر معرفة المبحوثين بالمستحدثات الزراعية الجديدة

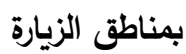

أوضحت بيانات جدول رقم (ع) أن الغالبية العظمى من

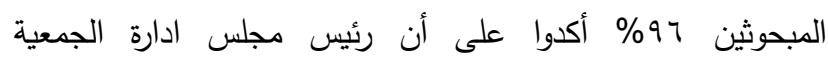

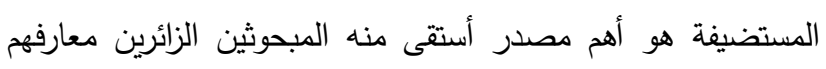

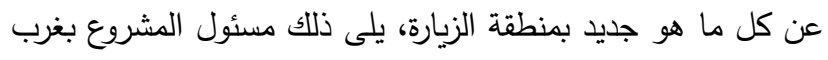

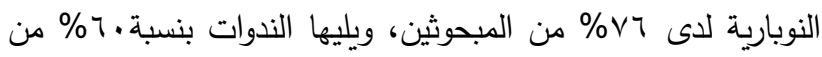


Scientific Journal of Agricultural Sciences 2 (2): 279-290, 2020

جدول \&. التكرارات والنسب المئوية لمصدر معرفة المبحوثين بالمستحدثات الزراعية بمنطقة الزيارة ن= ب

\begin{tabular}{|c|c|c|}
\hline$\%$ & 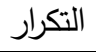 & مصدر المعرفة \\
\hline $97, \cdot$ & $r \varepsilon$ & l. رئيس الجمعية المستضيفة \\
\hline$\vee ч, \cdot$ & 19 & r. مسئول المشروع بغرب النوبارية \\
\hline $7 .$, & 10 & 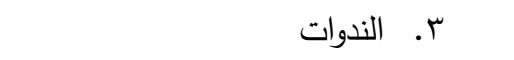 \\
\hline r^,. & $\checkmark$ & ع. النشرات والمطبوعات \\
\hline$\wedge, \cdot$ & r & ه. المضيفين من الزراع \\
\hline$\varepsilon, \cdot$ & 1 & ז. المشرف عن الزيارة التابع لنا \\
\hline
\end{tabular}

المصدر : إستمارة الإستبيان

وقد تمثلت أوجه استفادة المبحوثين من مكاسب اجتماعية

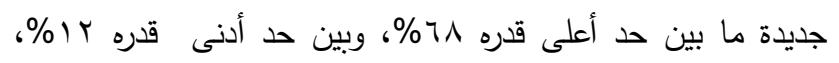

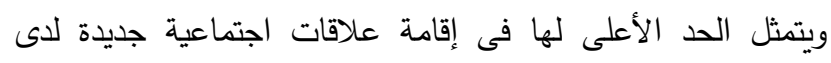

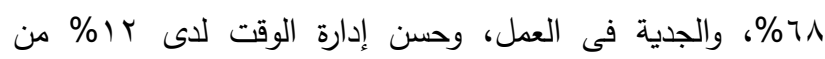

يتضح مما سبق أن جميع أوجه استفادة المبحوثين من

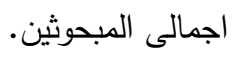

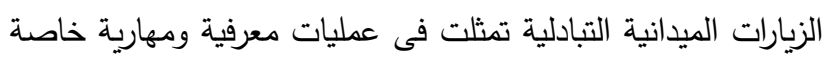

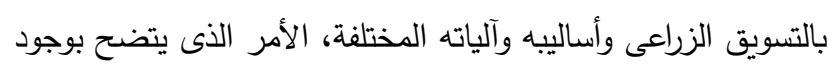

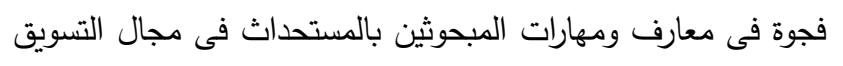

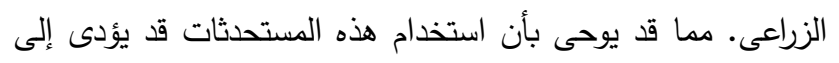
زيادة فى إنتاج وحداتهم، ويؤدى بدوره إلى زيادة فى مستوى دخولهم، وبالتالى تحسن فى مستوى معيشة أعضاء جمعياتهر.

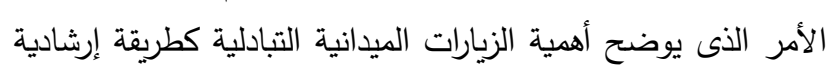

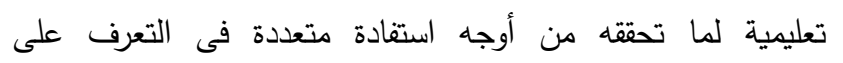
الممارسات المستحدثة لدى الزائرين.

\,. .امكانية تنفيذ المبحوثين للمستحثات المعروضة فى

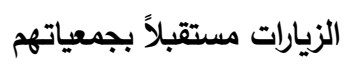

تبين من جدول رقم (؟) أن الغالبية العظمى من المبحوثين

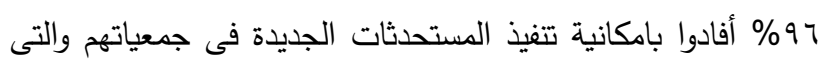
تعرفوا عليها أثناء الزيارة. بينما ؟ \% من المبحوثين أقروا بعدم أمكانيه تتفيذها.
عن المستحدث الزراعى للقيام بتعريف الزائرين بالمستحدث لأنه

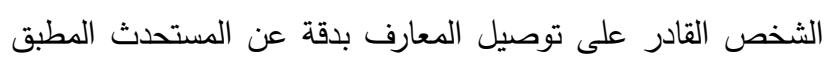
لديه.

4,0. أوجه استفادة المبحوثين من تعرضهم للزيارات الميدانية التبادلة بمنطقة غرب النوبارية

تبين من نتائج جدول رقم (0) تعدد وتتوع أوجه الاستفادة

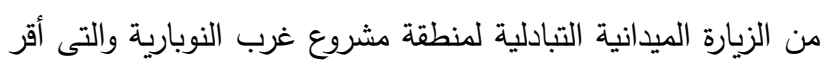

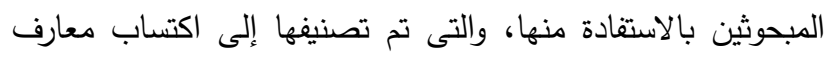
جديدة، واكتساب مهارات جديدة، وتحقيق مكاسب اجتماعية.

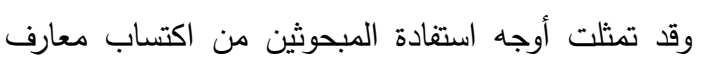

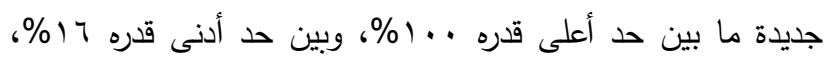

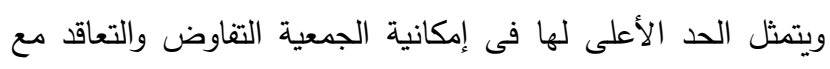
الثركات والزراع وأبرام العقود لدى ـ . 1\% من المبحوثين، وإمكانية

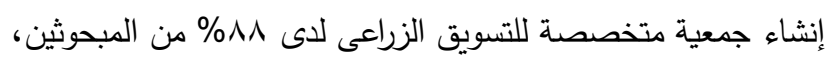

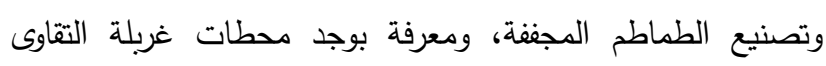

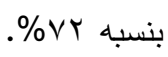
وتبين من نتائج جدول (0) أن أوجه استفادة المبحوثين من

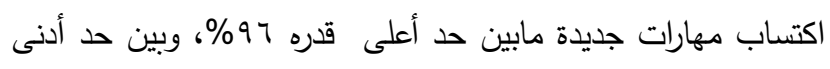

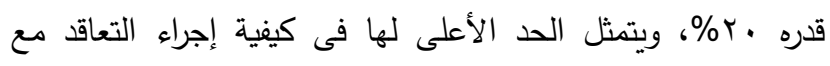

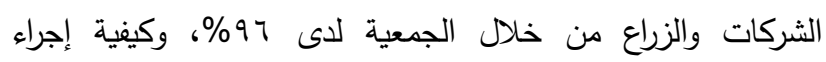

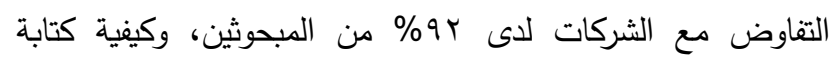

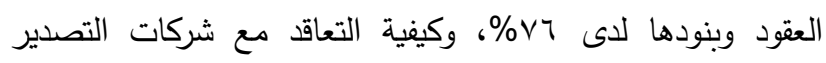

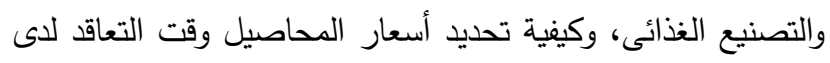

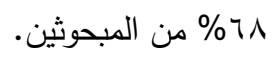


EIramily, M. A. A. A., 2020

جدول ه. التكرارات والنسب المئوية لأوجه الاستفادة من الزيارات الميدانية التبادلية لمنطقة غرب النوبارية

\begin{tabular}{|c|c|c|c|}
\hline$\%$ & التكرار & 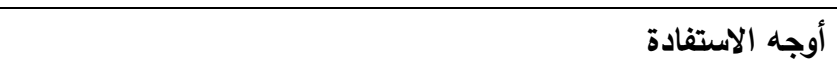 & م \\
\hline & & اكتساب معارف جديدة & أ- \\
\hline $1 \cdots$, & ro & امكانية الجمعية التفاوض والتعاقد مع الثركات والزراع وأبرام العقود & 1 \\
\hline$\wedge \wedge, \cdot$ & rt & إنشاء جمعية متخصصة للتسويق الزراعى & r \\
\hline$V Y$, & 11 & تصنيع الطماطم المجففة & r \\
\hline$V Y$, & 11 & المعرفة بوجود محطات غربله التقاوى & $\varepsilon$ \\
\hline$V Y$, & 11 & معرفة الزراعة التعاقدية & $\circ$ \\
\hline$\uparrow \varepsilon$, & 17 & تسويق المبيدات الحشرية & 7 \\
\hline $7 \varepsilon$, & 17 & طرق الرى الحديثة & $\checkmark$ \\
\hline $7 \cdot, \cdot$ & 10 & استخدام الطاقة الشمسية فى الرى & $\wedge$ \\
\hline or,. & ir & معرفة أنواع المحاصيل التصديرية & 9 \\
\hline$r_{\cdot, \cdot}$ & $\circ$ & التعرف على مزارع الأنتاج الحيوانى والداجنى عالية الانتاجية & 1. \\
\hline$r_{\cdot}, \cdot$ & ○ & التعرف على سلالات جديدة من الماشية مناسبة لدنطقة أسوان & 11 \\
\hline \multirow[t]{2}{*}{17,} & $\varepsilon$ & معرفة محاصيل عالية الانتاجية وذات قيمة تسويقة عالية & ir \\
\hline & & اكتساب مهارات جديدة & ب- \\
\hline 97, & $r \varepsilon$ & كيفية إجراء التعاقد مع الشركات والزراع من خلال الجمعية & 1 \\
\hline 9 १,. & rt & كيفية اجراء التفاوض مع الشركات & r \\
\hline V५, & 19 & كيفية كتابة العقود وبنودها & r \\
\hline $7 \wedge$, & iv & كيفية التعاقد مع شركات التصدير والتصنيع الغذائى & $\varepsilon$ \\
\hline$\uparrow \wedge$, & iv & كيفية تحديد أسعار المحاصيل وقت التعاقد & ○ \\
\hline$\varepsilon \wedge$, & ir & كيفية عمل تجميعات لمحصول القمح من الزراع وتوريدها للمطحن & 1 \\
\hline$\Sigma \wedge$, & ir & كيفية استخدام الطاقة الثمسية فى عملية الرى & $\checkmark$ \\
\hline$\varepsilon \wedge$, & ir & كيفية تتفيذ شبكات الرى المطور & $\wedge$ \\
\hline$\varepsilon \varepsilon$, & 11 & كيفية إنشاء الجمعيات التسويقية & 9 \\
\hline$\varepsilon \cdot, \cdot$ & 1. & كيفية زيادة موارد الجمعية بإنشاء محطة غربلة لتقاوى القدح. & 1. \\
\hline$\varepsilon \cdot$, & $1 \cdot$ & كيفية إنشاء تجميعة ومصنع ألبان لتصنيع الألبان ومنتجاتها بالجمعية & 11 \\
\hline$\varepsilon \cdot, \cdot$ & $1 \cdot$ & كيفية تصنيع الطماطم المجففة وتسويقها & Ir \\
\hline$r \cdot, \cdot$ & $\circ$ & كيفية عمل مزرعة حيوانية عالية الأنتاج & ir \\
\hline \multirow[t]{2}{*}{$r_{\cdot, \cdot}$} & $\circ$ & كيفية إختيار سلالات جيدة من المواشى & $1 \varepsilon$ \\
\hline & & اكتساب مهارات اجتماعية & ج- \\
\hline$\uparrow \wedge$, & iv & إقامه علاقات اجتماعية جديدة & 1 \\
\hline 17, & $\varepsilon$ & زيادة الثقة بالنفس وبقدراتتا & r \\
\hline Ir,. & $r$ & الجدية فى العمل & r \\
\hline ir,. & $r$ & حسن إدارة الوقت & $\varepsilon$ \\
\hline
\end{tabular}


Scientific Journal of Agricultural Sciences 2 (2): 279-290, 2020

جدول 4. توزيع المبحوثين وفقاً لامكانية تنفيذ المبحوثين للمستحدثات المعروضة أثناء الزيارات. ن=ه

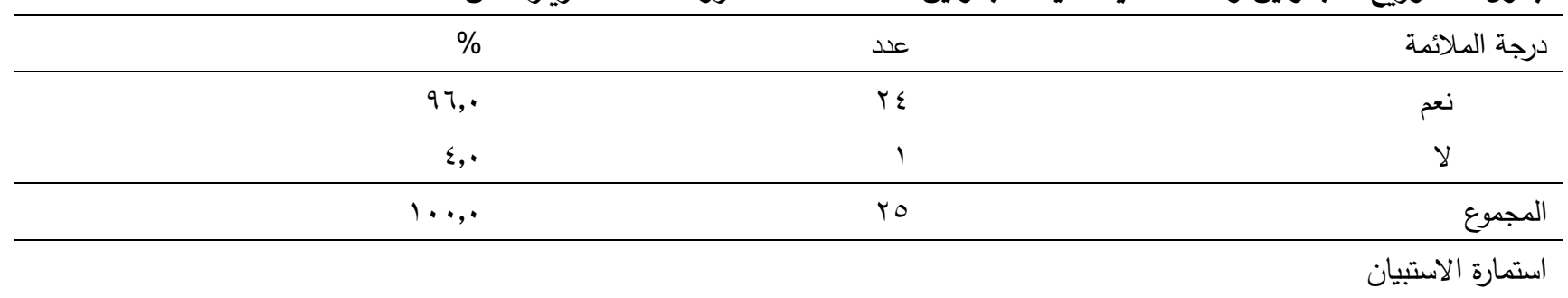

ويتضح من ذلك إرتفاع مستوى معرفة المبحوثين بأهمية المستحدثات التى تم مشاهدتها والتعرف عليها أثناء الزيارات الميدانية

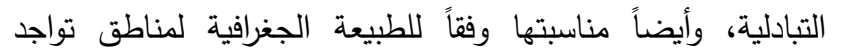
جمعياتهم التسويقية، وخصائص الزراع أعضاء الجمعيات، وهذا

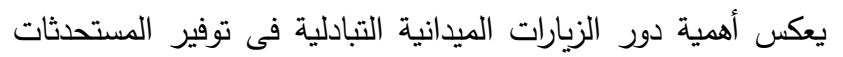

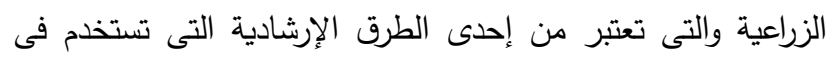
نشر المستحدثات وتبنيها وفقاً لسلم التبنى.

يتبين من نتائج جدول رقم (V) تعدد وتنوع الأفكار والمستحدثات

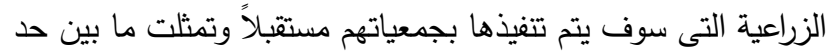
أعلى قدره r9\% ، وبين حد أدنى قدره ^\%؛، ويتمثل الحد الأعلى لها فى عمل تجميعات للقتح وتسويقها لشركة المطاحن، وعمل عقود تسويقيه مع الزراع أعضاء الجمعية والثركات الزراعية. وتمثل الحد

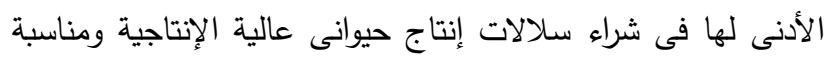
لأجواء محافظة اسوان، وإنشاء مصنع لتصنيع منتجات الألبان. جدول V. التكرارات والنسب المئوية للمستحدثات التى يمكن تنفيذها مران

\begin{tabular}{|c|c|c|c|}
\hline$\%$ & عدد & المستحدثات & \\
\hline $9 \mathrm{q}, \cdot$ & rt & عمل تجميعات للقصح وتسويقها لشركة المطاحن & 1 \\
\hline qr, & rt & عمل عقود تسويقية مع الزراع أعضاء الجمعية والثركات الزراعية & r \\
\hline$T \varepsilon, \cdot$ & 17 & تسويق المبيدات من خلال الجمعية & r \\
\hline 07,. & $1 \varepsilon$ & عمل محطة غربله للتقاوى & $\varepsilon$ \\
\hline 07,. & $1 \varepsilon$ & تركيب وحدة طاقة شمسية واستخدامها فى الرى & 。 \\
\hline or, & it & عمل برنامج تسميد للمانجو والقصح والنخيل & 1 \\
\hline rᄉ, & v & زراعة النعناع والريحان للتصدير & v \\
\hline $17, \cdot$ & $\varepsilon$ & عمل مجفف شمى لتجفيف الطماطم & $\wedge$ \\
\hline$\Lambda, \cdot$ & $r$ & شراء سلالات إنتاج حيوانى عالية الإنتاجية ومناسبة لأسوان & 9 \\
\hline ᄉ,. & r & وإنشاء مصنع لتصنيع منتجات الالبان & 1. \\
\hline
\end{tabular}

استمارة الاستبيان

צ, Y. أراء المبحوثين فى تنظيم الزيارة الميدانية التبادلية لمنطقة مرتفع، ومتوسط. بينما ^\% من المبحوثين يرون أن مستوى تتظيم الزيارات منخفض.

ويتضح من ذلك أن غالبية المبحوثين rو\% يرون أن مستوى تنظيم الزيارات الميدانية تتراوح بين المتوسط والعالى، وهذا لئها يتضح من نتائج جدول رقم (^) أن rو\% من إجمالى المبحوثين يرون أن مستوى تنظيم الزيارات الميدانية التبادلية بين إندان يعكس أرتفاع مستوى تتظيم الزيارة الميدانية التبادلية من خلال لتئي الجهات القائمة عليها.

جدول ^. توزيع المبحوثين وفقاً لمستوى أرائهم فى تنظيم الزيارة." ن= هب

\begin{tabular}{|c|c|c|c|}
\hline$\%$ & عدد & & مستوى التنظيم \\
\hline $7 \cdot, \cdot$ & 10 & $(\varepsilon r-r \varepsilon)$ & مستوى مرتفع \\
\hline rr,. & $\wedge$ & $(r-r \varepsilon)$ & مستوى متوسط \\
\hline$\wedge$, & r & $(Y r-1 \varepsilon)$ & مستوى منخفض \\
\hline $1 \cdots$, & ro & & المجوع \\
\hline
\end{tabular}

المصدر :استمارة لاستبيان 


\section{REFERENCES}

Bruns B (2002). Exchange Visits as a Learning and Networking Tool. Retrieved from hyperlink: https://dlc.dlib.indiana.edu/dlc/bitstream/handle/ 10535/4479/Bruns-Exchange_Visits.pdf

Desjardins R, Tuijnman A (2005). A General Approach for Using Data in The Comparative Analyses of Learning Outcomes. Interchange, 36(4). Retrieved from hyperlink: https://www.researchgate.net/publication/225617160 Hawkins ES, Southard B (2001). Field Tours And Old Tool That Can Still Work, Journal of Extension,39(1). Retrieved from hyperlink: https://www.joe.org/joe/2001february/tt4.php

Heiniger RW, Havlin JL, Crouse DA, Kvien C, Knowles T (2002). Seeing is Believing: The Role of Field Days and Tours in Precision Agriculture Education, Precision Agriculture 3(4): 309-318. Retrieved from hyperlink: https://link.springer.com/article/10.1023/A:10215 32603441

Lentfer J (2011). Exchange Visits Among Local Organizations-Here's How! , Retrieved from hyperlink:http://www.how-

matters.org/2011/10/02/exchange-visits-heres-how/

Maddy B, Gerber Ck, Hillger d (2015) Planning and Conducting Field Demonstration Tours, Journal of Extension,53(5). Retrieved from hyperlink: https://joe.org/joe/2015october/tt10.php

Matras F, Sidi F, Treinen S (2013). Exchange visits: Advice for improving the impact. (Fact Sheet) Rome: Knowledge Management and Gender, Food and Agriculture Organization (FAO). Retrieved from:

http://www.fao.org/docrep/019/aq213e/aq213e.pdf

Maunder, Addison H (1972). Agricultural Extension. A Reference Manual, FAO. Retrieved from hyperlink:

https://files.eric.ed.gov/fulltext/ED075628.pdf

Neil Rowe-Miller, Putso Nyathi (2017). Effective Extension Methods, Canadian Food grains Bank.

OAKLEY P, GARFORTH C (1985). Guide to extension training, FAO, Rome. Retrieved from hyperlink:

http://www.fao.org/3/t0060e/t0060e07.htm

Steingraber S, Bampton J (2017), Best Practices for Site Visits and Exchanges, An Analysis Prepared for the Climate and Land Use Alliance Retrieved from hyperlink: http://www.climateandlandusealliance.org/wpconten t/uploads/2017/11/Best-Practices-for-Site-Visitsand-Exchanges_FINAL.pdf

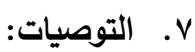

من عرض النتائج السابقة يمكن عرض بعض التوصيات

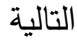

حيث أفادت النتائج إلى عدم مشاركة المرأة الريفية أو أى $-1$ من عضوات الجمعيات فى الزيارة، لذا فإن الدراسة توصى بإشراك المرأه عضو الجمعية التعاونية التسويقية فى الزيارات القادمة حتى تضمن الجمعيات مشاركة المرأة

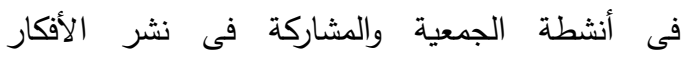
والمستحدثات بين اقرانهن من الريفيات.

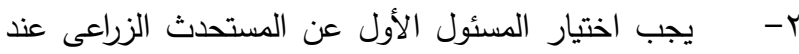

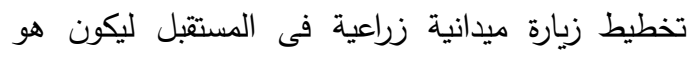
مصدر المعرفة للزائرين عن المستحدثات المراد نشرها. لتلقى القبول والاستحسان. r- استمرار استخدام الزيارات الميدانية التبادلية للجمعيات التعاونية التسويقية بالنقرة ووادى الصعايدة كطريقة تعليمية إرشادية فى مجالات أخرى للنتائج المثرة لتبادل المعرفة من خلال تبادل الزيارات الميدانية يعطى القدرة والثقة لدى الأفراد كما أظهرته نتائج الزيارة المدروسة.

ع- العمل على إبراز النواحى الايجابية للزيارات الميدانية التبادلية، وكذلك أوجه القصور للعمل على تلافيها وتكوين اتجاهات ايجابية نحو التغيير وتبنى المستحدثات الجديدة ^. بين أعضاء الجمعية.

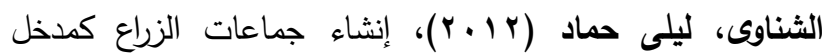

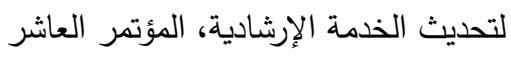

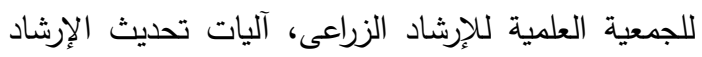

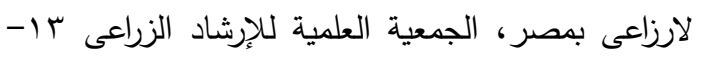

$$
\text { ع ا فبراير ، القاهرة. }
$$

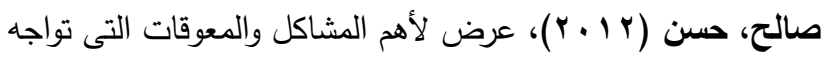
العمل الإرشادى مع بعض حضن الآليات

والأساليب المقترحة لها. المؤتمر العاشر للجمعية العلمية

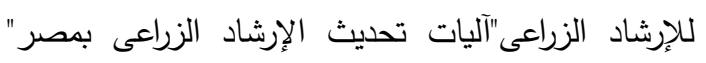

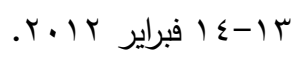

وزاره الزراعة واستصلاح الأراضى (Y. V V)، مشروع الاستثمارات الزراعية المستدامة، الايفاد، إدارة التوثيق الاصني

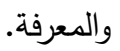


Scientific Journal of Agricultural Sciences 2 (2): 279-290, 2020

Development Practitioners. (2. Edition, Ed.) World Bank (2015). The Art of Knowledge Washington DC: The World Bank.

Exchange: A Results-Focused Planning Guide For

\title{
Exchange Site Visits And Their Role In Diffusion Agricultural Innovations In The Areas Of Wadi Al-Naqrah And Wadi Al-Saaida In Aswan Governorate
}

\author{
Elramily, M. A. A. A. \\ Agricultural Economics Department, Fac. Of Agric., Bani Sweif Univ., Egypt \\ Corresponding author email: elramily2011@yahoo.com
}

Received on: 16/11/2020

Accepted on: 6/12/2020

\begin{abstract}
The main objectives of the research are to identify the role of the exchange site visits as an extension education method in diffusion agricultural innovations in the areas of Wadi Al-Naqrah and Wadi Al-Saaida in Aswan Governorate. By identifying the aspects of the respondents' benefit from their exposure to site visits in the area of the West Nobareya project.

The research was conducted on a comprehensive amount of 25 respondents from members of agricultural marketing cooperative societies in Wadi Al-Sa idah and Al-Naqrah regions in Aswan Governorate. Data were collected through an interview questionnaire from October 2020. The results of this research revealed that:

The respondents' benefits varied from the exchange site visit: acquiring new knowledge and skills and achieving social gains.

Its upper limit was represented in the ability of the association to negotiate and contract with companies and farmers and conclude contracts with $100 \%$ of the respondents.

The majority of the respondents have specific goals in performing exchange site visits, which are to identify new marketing methods and to communicate with officials of associations in Nobarea, $88 \%$, and $72 \%$ of the respondents. $96 \%$ of the respondents can implement the new developments that they were exposed to during the visit.
\end{abstract}

KEYWORDS: Site visits- Exchange site visits- Method extension- Field trip- Tour extension 